\title{
SAÚDE NÃO É MERCADORIA
}

Exatamente porque saúde não é mercadoria, a regulação sanitária ganha relevo no mundo capitalista. O atual escândalo conhecido como Implant Files é suficiente para demonstrar que o apetite das empresas atuantes nessa área é insaciável e que, sem adequada regulação e atenta vigilância sobre elas, serão altamente prejudicados não só os pacientes (no caso, com sequelas provocadas por produtos de baixa qualidade e inadequados à necessidade), mas também os sistemas de saúde, que além de arcarem com os custos decorrentes da compra dos implantes, devem suportar os encargos de cuidar das sequelas e de eventual indenização.

Essa introdução é necessária para matizar a imagem de que há necessidade de proteção patentária para garantir que os investimentos em pesquisa e desenvolvimento retornem ao inventor dos medicamentos e dispositivos médicos, promovendo um círculo virtuoso: maiores investimentos gerando melhores produtos. Vários e importantes fatores, inclusive a saúde dos pacientes e dos sistemas de saúde, interferem nesse círculo. Certamente, também é um deles a criação da Organização Mundial do Comércio (OMC), em 1994, com a assinatura do Acordo sobre os Aspectos da Propriedade Intelectual Relacionados ao Comércio (Acordo TRIPS) ${ }^{1}$. O aprofundamento das iniquidades em relação ao acesso a medicamentos e tecnologias resultou na Declaração de Doha sobre o Acordo TRIPS e Saúde Pública ${ }^{2}$, em 2001, buscando algum equilíbrio entre os fatores lembrados. A Declaração é uma tentativa multilateral de reforçar o direito dos países em desenvolvimento de utilizarem as flexibilidades presentes no TRIPS. Pretendia-se mitigar os efeitos adversos das políticas de propriedade intelectual, adequando-as às necessidades de saúde pública dos países em desenvolvimento.

No âmbito propriamente sanitário, a Organização Mundial da Saúde (OMS) buscou contribuir para o encontro do equilíbrio ótimo entre os direitos de propriedade intelectual e inovação e os interesses da saúde pública. Em 2003, ela instituiu a Comissão sobre Direitos de Propriedade Intelectual, Inovação e Saúde Pública, germe da Estratégia Global e Plano de Ação sobre Saúde Pública, Propriedade Intelectual e Inovação, aprovada em 2008 com o principal objetivo de "promover um novo pensamento sobre a inovação e o acesso a medicamentos [...] que garanta uma base sólida e sustentável para a pesquisa e o desenvolvimento em saúde guiados pelas necessidades e centrados

\footnotetext{
${ }^{1}$ BRASIL. Decreto $n \cdot 1.355$, de 30 de dezembro de 1994. Promulgo a Ata Final que Incorpora os Resultados da Rodada Uruguai de Negociações Comerciais Multilaterais do GATT. Disponível em: <http://www.inpi.gov.br/ legislacao-1/27-trips-portugues1.pdf>.

${ }^{2}$ WORLD TRADE ORGANIZATION - WTO. Declaration on the TRIPS agreement and public health. Disponivel em: <https://www.wto.org/english/thewto_e/minist_e/min01_e/mindecl_trips_e.htm>.
} 
em doenças que afetam desproporcionalmente países em desenvolvimento"'3. Esse importante documento traz, entre seus oito grandes capítulos, um inteiramente dedicado à aplicação e gestão do regime de propriedade intelectual para contribuir para a inovação e promover a saúde pública. Pode-se afirmar, portanto, que existe um consenso internacional relacionado à saúde que reconhece ser necessário explorar alternativas que mitiguem os efeitos deletérios provocados pela propriedade intelectual no acesso a medicamentos pelos países em desenvolvimento.

Busca-se melhorar a capacidade de usar todos os instrumentos previstos no Acordo TRIPS e reforçados pela Declaração de Doha para adequar sua aplicação considerando a proteção da saúde pública. Assim (i) a licença compulsória, ou permissão, por parte do governo de um país para que o medicamento seja fabricado por uma terceira parte, sem a permissão do proprietário da patente; (ii) a importação paralela, que, como mecanismo de arbitragem, é fundamental para limitar a capacidade da empresa detentora de patentes de medicamentos de exercer seu poder de mercado e obter um preço de monopólio por seu produto; e (iii) e a exceção Bolar, quando é concedido a uma empresa o direito de desenvolver todos os procedimentos necessários para solicitar a aprovação pelas autoridades sanitárias nacionais de sua versão de medicamento patenteado antes da expiração da patente, com vistas a sua introdução no mercado quando do fim do período de vigência da patente, visando à obtenção de medicamentos a preços mais razoáveis, seja por meio da entrada de versões genéricas de medicamentos, seja por meio da importação de produtos que estejam sendo comercializados internacionalmente a preços inferiores aos praticados no país. Estas são medidas capazes de produzir efeito imediato. Outros instrumentos visam a estimular o desenvolvimento tecnológico dos Estados menos desenvolvidos, como o uso experimental e a atuação do setor de saúde nos processos de pedidos de patentes farmacêuticas. Melhorar a capacidade de usar tais instrumentos é indispensável face ao comportamento potencialmente danoso que vem caracterizando as grandes indústrias farmacêuticas para a extensão do prazo de exclusividade sobre o produto, gerado pela proteção patentária, como é o caso das categorias informais conhecidas como sham litigation (forma fraudulenta de acessar o Judiciário, sem qualquer perspectiva de sucesso, com a finalidade de causar prejuízo a terceiro), do evergreening (obtenção de patentes secundárias cobrindo diferentes usos, formulações e polimorfos de um ingrediente básico) e do forum shifting (busca do foro que melhor atenda a seus interesses na disputa judicial).

Hoje são preocupações globais o fato de ser possível ao fabricante do medicamento definir o preço tão alto quanto se pode especular que as pessoas estariam dispostas a pagar; o desabastecimento de medicamentos; e a incorporação de novas

${ }^{3}$ WORLD TRADE ORGANIZATION - WTO. WHA59.24 - Public health, innovation, esse ntial health research and intellectual property rights: toward s a global strategy and plan of action. Disponivel em: <https://www.who. int/phi/Res59_R24-en.pdf>. 
tecnologias, que se acentua com o advento dos medicamentos biológicos, o déficit tecnológico dos países em desenvolvimento e a ausência de biossimilares no mercado.

O Brasil tem revelado um comportamento hesitante nesse campo: começou não utilizando o tempo de transição possibilitado pelo Acordo TRIPS para concessão de patentes farmacêuticas, permitindo o reconhecimento retroativo pelo prazo remanescente da proteção denominado pipeline (Lei n. 9.279/1996, arts. 230 e 231); e adotou o regime nacional de exaustão de direitos, instituto diretamente ligado à possibilidade - ou não - da importação paralela de medicamentos. Neste caso, após introduzir no mercado o produto que incorpora a invenção patenteada, o titular da patente não pode mais impedir sua livre circulação. Isso significa que um terceiro, ao adquirir o produto, pode dele dispor livremente e que o titular da patente perde a faculdade de proibir a importação do produto. Há uma corrente doutrinária que entende que, sendo cabível a exigência da exploração local pela legislação nacional, a importação não pode ser considerada ato de exploração; e que será lícita a importação de qualquer produto patenteado, mesmo quando não colocado no mercado nacional pelo detentor da patente, quando a legislação nacional optar pela exaustão internacional do direito.

Em seguida, o país se valeu do mecanismo do licenciamento compulsório apenas uma vez, tornando ineficazes as constantes ameaças a seu emprego. E vem recorrendo ao licenciamento voluntário, um instrumento de base comercial, por meio de Parcerias para o Desenvolvimento Produtivo (PDP). Note-se que a essência do negócio de tais parcerias une a transferência de tecnologia ao fornecimento do produto, deixando de incentivar a produção nacional de ingrediente farmacêutico ativo.

Um caso emblemático do comportamento brasileiro nesse campo é o conflito atual, que ganhou espaço nos grandes meios de comunicação, em torno do remédio contra a hepatite C. Em junho de 2018, foi anunciado o plano pactuado entre o Ministério da Saúde, estados e municípios para tratar todos os casos de hepatite C até 2030, em consonância com as metas da OMS. Na ocasião, a diretora do Departamento de Vigilância, Prevenção e Controle das IST, HIV/Aids e Hepatites Virais do Ministério da Saúde afirmou que diagnosticar e tratar os portadores do vírus era "essencial para a qualidade de vida dessas pessoas e também para a saúde pública"4. Pois bem, unindo a transferência de tecnologia ao fornecimento do produto, a PDP envolvendo o Instituto de Tecnologia em Fármacos (Farmanguinhos/Fiocruz) e os laboratórios nacionais Blanver Farmoquímica e Farmacêutica S.A. e Microbiológica Química e Farmacêutica LTDA permitiu que o Farmanguinhos/Fiocruz obtivesse o registro do sofosbuvir $400 \mathrm{mg}$, principal medicamento para hepatite C. Foi com

${ }^{4}$ SAÚDE lança plano para eliminar hepatite C. Ministério da Saúde, 05 de Julho de 2018. Disponível em: <http://portalms.saude.gov.br/noticias/agencia-saude/43763-ministerio-da-saude-lanca-plano-para-eliminar-hepatite-c-ate-2030>. 
base nesse registro (de 2 de julho de 2018) que o governo iniciou a distribuição do produto no Sistema Único de Saúde (SUS) 5 . De outro lado, em abril de 2004, a empresa Gilead PharmasseT LLC apresentou pedido de patente de invenção junto ao Instituto Nacional de Propriedade Industrial (INPI), e a anuência prévia a ser dada pela Agência Nacional de Vigilância Sanitária (Anvisa) foi amplamente questionada. Também o Farmanguinhos/Fiocruz apresentou, em fevereiro de 2017, subsídio ao exame técnico do pedido de patente, alegando não ser ele passível de patenteabilidade por não apresentar novidade e atividade inventiva (requisitos necessários para a concessão de patente) ${ }^{6}$. Em maio de 2017, a Anvisa anuiu e, em setembro de 2018, o INPI concedeu a patente à farmacêutica norte-americana, impedindo o Farmanguinhos/Fiocruz de produzir o sofosbuvir genérico, que já estava registrado pela Anvisa.

Imediato clamor contra a decisão de concessão do INPI resultou, por exemplo, em manifestação da organização humanitária Médicos Sem Fronteiras, que considera que o "posicionamento do órgão brasileiro responsável pela análise de patentes ocorreu a despeito de haver sólidos argumentos contrários à concessão" . Dois dias depois, foi protocolado pedido de anulação do ato administrativo que outorgara a patente do fármaco antiviral, imediatamente concedido ${ }^{8}$. Também a Associação Brasileira de Saúde Coletiva (Abrasco) e o Grupo de Trabalho sobre Propriedade Intelectual da Rede Brasileira pela Integração dos Povos (GTPI/Rebrip) pediram ao Ministro da Saúde a imediata decretação do interesse público do medicamento, providência essencial a seu eventual licenciamento compulsório9.

Hoje, a anulação liminar da patente sobre o sofosbuvir concedida à empresa Gilead ainda é mantida e o imbróglio também, pois ainda falta saber "se o governo comprou o melhor remédio pelo menor preço" ${ }^{10}$. E a questão permanecerá em aberto enquanto a humanidade não for capaz de introjetar a compreensão de que saúde não

\footnotetext{
${ }^{5}$ RELATO Reunião para Reavaliação do PCDT de Hepatite C. Disponível em: <http://www.aids.gov.br/sites/default/files/noticia/2018/65918/relato_da_reuniao_para_reavaliacao_do_pcdt_de_hepatite_c_003.pdf>. ${ }^{6}$ BRASIL. Ministério da Saúde. Fundação Oswaldo Cruz - Fiocruz. Compostos, composições e usos para o tratamento de uma infecção por flaviviridae. Disponível em: <http://www.far.fiocruz.br/wp-content/uploads/2017/02/Subsidio-pedidoPatenteSofosbuvir.pdf>.

${ }^{7}$ MELLO, Patrícia Campos. Governo libera patente de remédio para hepatite $C$ de americana e trava genérico mais barato. Folha de S. Paulo, São Paulo, 18 set. 2018. Disponível em: <https://www1.folha.uol. com.br/cotidiano/2018/09/governo-libera-remedio-para-hepatite-c-de-americana-e-trava-generico-mais-barato.shtml>.

${ }^{8}$ BRASIL. Tribunal Federal Regional da $1^{\text {a }}$ Região. Patente, ato lesivo ao patrimônio artístico, estético, histórico ou turístico, dano ao erário. Consultor Jurídico. Disponível em: <https://www.conjur.com.br/dl/ acao-popular-hepatite.pdf>.

${ }^{9}$ ASSOCIAÇÃO BRASILEIRA DE SAÚDE COLETIVA - ABRASCO. Grupo de Trabalho sobre Propriedade Intelectual. Rio de Janeiro, 28 set. 2018. Disponível em: <https://www.abrasco.org.br/site/wp-content/uploads/2018/09/Abrasco_GTPI_MS_sofosbuvir.pdf>.

${ }^{10}$ LEITE, Marcelo. Confusão sem fim na hepatite C. Folha de S. Paulo, São Paulo, 09 dez. 2018. Disponível em: <https://www1.folha.uol.com.br/colunas/marceloleite/2018/12/confusao-sem-fim-na-hepatite-c.shtml>.
} 
é mercadoria e não pode ser tratada como tal. Não alterar tal compreensão significa colocar-se no papel de Sísifo, sempre tentando manter afastados os danos causados - aos pacientes e aos sistemas de saúde - por produtos e tratamentos de baixa qualidade, inadequados ou impagáveis e irremediavelmente ligados a esses danos.

Sueli Gandolfi Dallari

Editora científica 